\title{
PEMBUATAN SYSTEM CORPORATE MESSENGER PADA JARINGAN LAN
}

\author{
Lily Puspa Dewi ${ }^{1}$, Remuz MB Kmurawak ${ }^{2}$, Petrus Santoso ${ }^{2}$ \\ 1) Jurusan Teknik Informatika, Universitas Kristen Petra, Surabaya, 60236 \\ 2) Jurusan Teknik Elektro, Universitas Kristen Petra, Surabaya, 60236 \\ Email: lily@petra.ac.id
}

\begin{abstract}
ABSTRAK: Corporate messenger merupakan suatu aplikasi yang dapat digunakan untuk berkomunikasi dalam sebuah Local Area Network. Hal ini dilatarbelakangi oleh perlu adanya proses pengiriman pesan secara bersama-sama dalam sebuah Local Area Network. Pesan yang ingin dikomunikasikan tidak hanya berupa teks, tetapi dapat juga menggunakan video maupun audio Komputer client akan melakukan koneksi dengan server. Jika sudah terjadi koneksi dengan server, maka client tersebut akan melanjutkan dengan autentikasi dan kemudian dapat melakukan pengiriman pesan dengan client yang telah terdaftar dalam database server. Pengiriman pesan audio dan video terjadi dengan koneksi peer to peer dengan terlebih dahulu memasukkan IP address dari remote user yang ingin diajak berkomunikasi. Pengujian dilakukan dengan menggunakan tiga buah komputer dan diperoleh bahwa proses autentikasi dapat berjalan dengan baik, pengiriman pesan teks dapat dilakukan dengan baik dan komunikasi dengan menggunakan audio dapat didengar dengan jelas. Khusus untuk pengiriman pesan dengan menggunakan video dapat langsung dilihat pada remote client. Rata-rata waktu yang dibutuhkan untuk menampilkan video pada remote client adalah 3.71 detik.
\end{abstract}

Kata kunci: Local Area Network, Messenger, Client server

\begin{abstract}
Corporate messenger is the one of the application that can be used for communication in a local area network. The backgrounds of this topic are needs of sending message process in the LAN. The messages which want to be presented are not only in a text format, but also can be in audio visual format. Computer client will connect to the server. When the connection has been established, the client continued the authentication and started sending message between client and server. Audio and video message sending can be done with peer to peer connection with entering the IP address first from remote user that we want to communicate with. The evaluation of this application was done by using 3 computers and as the result, we found that authentication process can work properly, sending text message was done properly and communication using audio can be heard clearly. In addition to video sending message, we could see directly in remote client. The average time to show the video on remote client is 3.771 seconds.
\end{abstract}

Keyword: Local Area Network, Messenger, Client server

\section{PENDAHULUAN}

Kebutuhan komunikasi saat ini tidak dapat dihindari lagi dari tuntutan terhadap kecepatan dan ketepatan penyampaian pesan, sistem yang reliabel dan berbagai macam bentuk pesan. Dalam teknologi komunikasi dengan menggunakan komputer, bagian yang memegang peranan yang signifikan adalah jaringan. Arsitektur jaringan sendiri sebenarnya merupakan dasar dari telekomunikasi dengan menggunakan komputer.

Setiap perusahaan dalam bidang telekomunikasi pun sedang gencar untuk membuat aplikasi yang berhubungan dengan masalah jaringan ini. Keberadaan corporate messenger juga merupakan salah satu bentuk dari kemajuan teknologi yang pada beberapa tahun terakhir mengalami perkembangan yang sangat signifikan. Seperti misalnya pengembangan voice over IP, tunelling, Virtual LAN, dan lain sebagainya.. Berbagai macam kegunaan dapat diperoleh dengan menggunakan corporate messenger khususnya dapat mengatasi masalah jarak, waktu dan biaya dalam komunikasi.

Corporate messenger dirancang sebagai aplikasi yang digunakan dalam komunikasi antara satu client dengan beberapa client lainnya dengan sebuah server di dalam sebuah jaringan. Aplikasi ini memungkinkan terjadi komunikasi secara bersamaan antara client yang ada. Secara umum pesan yang disampaikan antara client ini dapat berupa pesan dalam bentuk teks, video maupun dalam bentuk audio. Aplikasi ini dibangun dengan menggunakan Microsoft Visual C\# pada platform .NET Framework. 


\section{NET FRAMEWORK}

"NET Framework" terdiri dari dua buah komponen utama, yaitu Common Language Runtime (CLR) dan “.NET Framework” Class Library atau kadang juga sering disebut dengan Base Class Library (BCL).

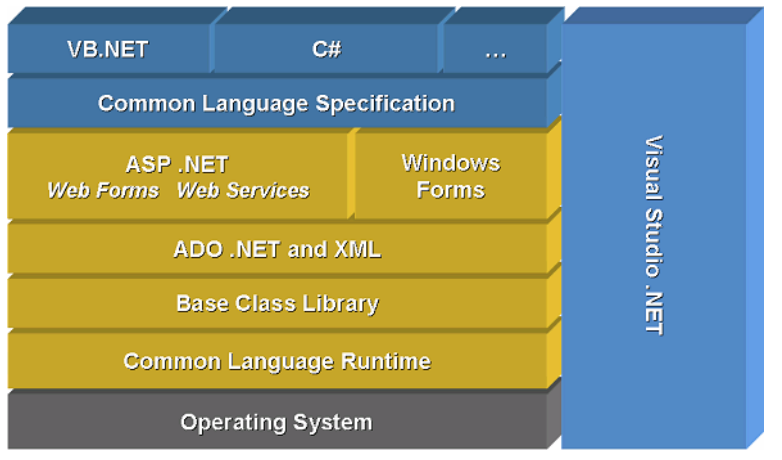

Gambar 1. Arsitektur dari “.NET Framework” http://www.obout.com/show/images/ NETFramework3.png

\section{Common Language Runtime (CLR)}

Common Language Runtime (CLR) adalah pondasi utama dari “.NET Framework". CLR merupakan komponen yang bertanggung jawab untuk melakukan manajemen memory, melakukan eksekusi kode, melakukan verifikasi terhadap keamanan kode, menentukan hak akses dari kode, melakukan kompilasi kode dan berbagai layanan sistem lainnya.

Dengan adanya fungsi $C L R$ ini, maka aplikasi berbasis .NET biasa juga disebut dengan managed code, sedangkan aplikasi di luar itu biasa disebut dengan un-managed code.

CLR melakukan kompilasi kode-kode aplikasi kita menjadi bahasa assembly MSIL (Microsoft Intermediate Language). Proses kompilasi ini sendiri dilakukan oleh komponen yang bernama Just In Time (JIT).

\section{“.NET Framework” Class Library (Base Case Library)}

“.NET Framework" Class Library atau sering juga disebut Base Case Library (BCL) adalah koleksi dari reusable types yang sangat terintegrasi secara melekat dengan CLR. Class library bersifat berorientasi terhadap object yang akan menyediakan types dari fungsi-fungsi managed code. Hal ini tidak hanya berpengaruh kepada kemudahan dalam hal penggunaan, tetapi juga dapat mengurangi waktu yang diperlukan pada saat eksekusi. Dengan sifat tersebut maka komponen pihak ketiga akan dengan mudah diaplikasikan ke dalam aplikasi yang dibuat.
Dengan adanya BCL ini maka kita bisa menggunakan .NET Framework untuk membuat berbagai macam aplikasi, seperti :

- Aplikasi console

- Aplikasi berbasis windows (Windows Form)

- Aplikasi ASP.NET (berbasis web)

- Aplikasi Web Services XML

- Aplikasi berbasis Windows Services

Jika kita membuat sekumpulan class untuk membuat aplikasi berbasis Windows, maka class itu bisa kita gunakan untuk jenis aplikasi lain, seperti aplikasi berbasis web (ASP.NET).

\section{NET REMOTING}

Microsoft “.NET Remoting” menyediakan sebuah kerangka yang mengijinkan object untuk berinteraksi antara satu dengan yang lainnya melintasi batasan aplikasi. Kerangka tersebut menyediakan beberapa services, termasuk aktivasi dan lifetime support, sebagaimana komunikasi channel bertanggungjawab terhadap pengiriman pesan dari dan kepada aplikasi remoting yang ada [1].

Formater digunakan untuk encoding dan decoding pesan sebelum pesan-pesan tersebut dikirimkan melalui channel. Aplikasi dapat menggunakan binary encoding untuk programprogram yang kritikal atau XML untuk programprogram yang lebih esensial.

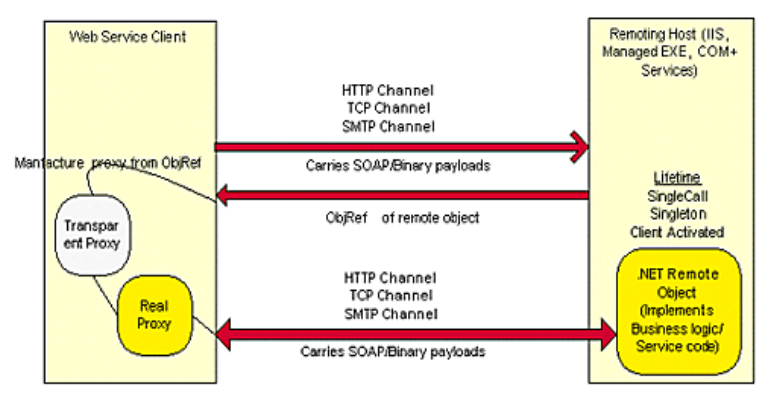

Gambar 2. Arsitektur dari “.NET Remoting” [1]

Formater digunakan untuk encoding dan decoding pesan sebelum pesan-pesan tersebut dikirimkan melalui channel. Aplikasi dapat menggunakan binary encoding untuk programprogram yang kritikal atau XML untuk programprogram yang lebih esensial.

Semua XML encoding menggunakan SOAP protocol dalam pengiriman pesan dari satu domain aplikasi ke domain aplikasi lainnya. Remoting telah didesain dengan security in mind dan sekumpulan protocol yang mengijinkan channel sinks untuk 
memperoleh akses kepada pesan-pesan dan serialized stream sebelum stream tersebut dialirkan.

Mengatur lifetime dari remote object tanpa support yang mendasar dari Framework seringkali tidak praktis. ".NET Remoting” menyediakan sekumpulan model aktivasi yang memungkinkan dari mana aktivasi ini akan dijalankan. Model-model ini dibagi ke dalam dua kategori:

1. Client Activated Object

2. Server Activated Object

Client activated object dibawah kontrol dari lease based lifetime manager yang akan memastikan bahwa object akan terkumpul ketika masa pemakaiannya telah selesai. Di dalam kasus dari server activated object developer dapat memilih untuk menggunakan single call atau singleton model. Lifetime dari singleton juga dikontrol oleh lease-based lifetime.

\section{REMOTE OBJECT}

Salah satu dari tujuan utama dari kerangka remoting adalah menyediakan infrastruktur yang diperlukan untuk menghilangkan kompleksitas dari pemanggilan methods dari remote object dan mengembalikan hasil. Beberapa object diluar domain aplication harus di-remote dengan hati-hati bahkan jika object tersebut dieksekusi pada mesin yang sama. Di dalam aplikasi domain, semua object dilewati oleh referensi, sementara primitive data type dilewati oleh nilainya.

Semua object yang dapat melintasi batasan domain aplikasi harus melewatkan nilainya dan harus ditandai dengan atribut serializable atau object tersebut harus dapat mengimplementasikan Iserizable interface. Ketika object dilewatkan sebagai parameter, kerangka “.Net Framework" akan menyusunnya secara berurut-urut dan kemudian akan dikirimkan ke domain aplikasi yang dituju, dimana object tersebut akan direkonstruksi (disusun kembali). Local Object yang tidak disususn secara serial tidak dapat dilewatkan kepada domain aplikasi lainnya.

Beberapa object dapat diubah menjadi remote object dengan mengacu kepada MarshalByRefObject. Ketika sebuah client mengaktifkan remote object, remote object tersebut akan menerima sebuah proxy kepada remote object tersebut [2].

Semua operasi dari proxy ini akan disesuaikan secara tidak langsung untuk memungkinkan infrastruktur dari “.NET Remoting” untuk menerima dan mem-forward panggilan tersebut. Secara tidak langsung mempunyai sedikit pengaruh pada performance tapi JIT compiler dan EE (Execution Engine) telah dioptimasi untuk mencegah terjadinya performance penalty.

\section{Channel}

Channel digunakan untuk mengantar pesan dari dan untuk remote object. Ketika sebuah client memanggil sebuah method dari remote objects, maka parameternya akan langsung dikirimkan melalui channel kepada remote object. Beberapa hasil dari panggilan tersebut akan dikembalikan kepada client melalui jalan atau cara yang sama. Sebuah client dapat memilih beberapa channel yang sudah terdaftar pada server untuk dapat berkomunikasi dengan remote object, dengan demikian memungkinkan developer secara bebas untuk memilih channel sesuai dengan kebutuhan yang diinginkan.

\section{HTTP Channel}

HTTP channel mengririmkan pesan kepada dan dari remote object menggunakan SOAP Protokol. Semua pesan yang ada akan dilewatkan melalui SOAP formater. Ketika pesan tersebut berubah menjadi $X M L$ dan diurutkan, dan SOAP header yang dibutuhkan akan ditambahkan ke dalam aliran data. HTTP channel juga memungkinkan untuk mengkonfigurasi dengan menggunakan binary formater. Hasil dari data stream ini akan dikirimkan kepada target dari URI dengan menggunakan protokol HTTP.

\section{TCP Channel}

TCP Channel menggunakan binary formater untuk mengurutkan semua pesan ke dalam aliran binary dan aliran data sersebut akan dikirimkan kepada target URI dengan menggunakan Protokol $T C P$. Ini juga memungkinkan untuk mengkonfigurasi TCP Channel untuk menggunakan SOAP formater.

\section{Activation}

Remoting Framework mendukung aktivasi server dan client untuk remote object. Server activation itu biasanya digunakan ketika remote object-nya tidak membutuhkan untuk pemeliharaan beberapa keadaan antara method yang dipanggil. Ini juga digunakan dalam kasus ketika banyak client memanggil method dalam object yang sama.

\section{TAPI (TELEPHONE APPLICATION PROGRAMMING INTERFACE)}

TAPI yang saat ini sudah mencapai versi 3 ini merupakan COM (Component Object Model ) interface yang memberikan kontrol komputer (berdasarkan IP) dalam memanfaatkan aplikasi 
telephone. Hal ini memungkinkan adanya aplikasi dari panggilan suara sederhana melalui Public Switched Telephone Network (PSTN) sampai kepada multicast IP conferencing dengan quality of service (QOS) yang dapat dikembangkan dengan berbagai macam programming language. Terdapat tiga komponen utama dari TAPI [3], yaitu:

- Service Provider menggambarkan secara spesifik mengenai mekanisme transport dari media. Service provider ini biasanya berjalan sebagai pasangan sebuah Telephony Service Provider (TSP) untuk call control dan sebuah Media Service Providers (MSPs) untuk media control.

- Telephony Service Providers (TSPs) adalah sebuah dinamic-link library (DLL) yang bertanggungjawab terhadap komunikasi antar telephony device (contoh: modem)

- Media stream Providers (MSPs) mengijinkan aplikasi melakukan kontrol terhadap mekanisme pertukaran data. MSP selalu berpasangan dengan TSP.

Tampilan diagram yang dapat mengilustrasikan arsitektur dari TAPI 3 dapat dilihat pada Gambar 3.

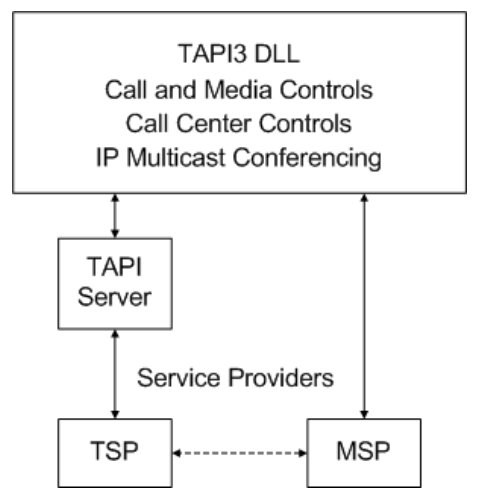

\section{Gambar 3. Arsitektur TAPI 3 http:/i.msdn. microsoft.com/ms734214.callarc_gif_1( en-us,VS.85). gif}

\section{PERANCANGAN SISTEM}

Secara garis besar, Corporate Messenger merupakan aplikasi yang bertujuan untuk mengirimkan dan menerima pesan (multimedia: teks, audio, video) dari satu komputer ke komputer lainnya dalam satu local area network. Satu dari komputer tersebut berfungsi sebagai server yang mengatur proses komunikasi data antar komputer, sedangkan komputer client adalah komputer yang berkomunikasi.

Pembangunan koneksi antara client dengan server dilakukan dengan memanfaatkan port yang tidak terpakai yaitu 7980. Server selalu dalam kondisi listening pada port tersebut untuk mengantisipasi request client yang datang. Sedangkan di sisi client, akan melakukan inisialisasi komunikasi pada port tersebut berdasarkan pada IP Address Server.

Setiap user yang akan menggunakan aplikasi ini diharuskan untuk registrasi dulu. Proses Registrasi akan menyimpan data user ke dalam file di server. Setelah registrasi, user akan diminta sign in pada aplikasi client dan kemudian setelah koneksi dengan server terbentuk, pengiriman dan penerimaan pesan multimedia dapat dilakukan antara computer client. Untuk penggunaan lebih lanjutnya file di server akan menyimpan:

- Username (dalam bentuk variabel string )

- Password username ( dalam bentuk variabel string )

- List contact dari username ( dalam bentuk arraylist )

- Offline Messagge ( dalam bentuk variabel string )

Protokol setup koneksi antara client dan server dapat dilihat pada Gambar 4.

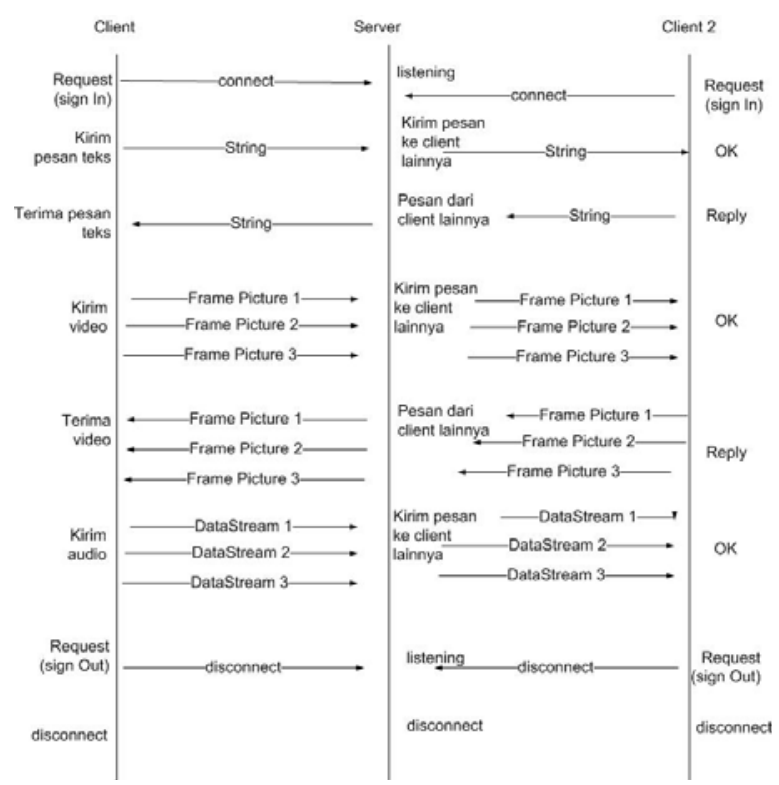

Gambar 4. Time Sequence Diagram mengenai Koneksi Antara Client dan Server Secara Umum. Arsitektur dari “.NET Remoting”

Proses pengiriman pesan yang berbentuk text akan dilakukan client dengan memanfaatkan variabel string yang menyimpan informasi from, to dan message kemudian dikirimkan ke server. Di server akan diterima oleh sebuah variabel yang menyimpan informasi from, to dan message. Variabel ini akan disimpan dalam bentuk file. Saat client yang dituju online, message akan dikirim oleh server.

Sedangkan untuk pengiriman pesan yang berbentuk multimedia memanfaatkan .NET Socket 
dan TAPI (Telephone Application Programing Interface). Khusus pengiriman pesan yang berupa video dilakukan dengan webcam. Sebelum komunikasi antara client dilakukan, terlebih dulu dilakukan inisialisasi antara webcam dengan komputer client yang terhubung dengan webcam tersebut. Inisialisasi mempunyai tahapan sebagai berikut:

- Koneksi program client dengan device yang ada, yaitu webcam (proses inisialisasi device)

- Menentukan skala video untuk preview

- Menentukan preview rate (satuan milisecond)

- Starting preview image dari kamera

- Pengiriman video dengan menggunakan port 6000.

Setelah inisialisasi dengan webcam selesai dilakukan, client akan mengubah video menjadi bitmap image dan akan disimpan dalam bentuk binary menjadi sebuah stream yang dikirimkan ke ke client yang dituju berdasarkan IP address (peer to peer). Diagram tahapan pengiriman image dan flowchart dapat dilihat pada Gambar 5.

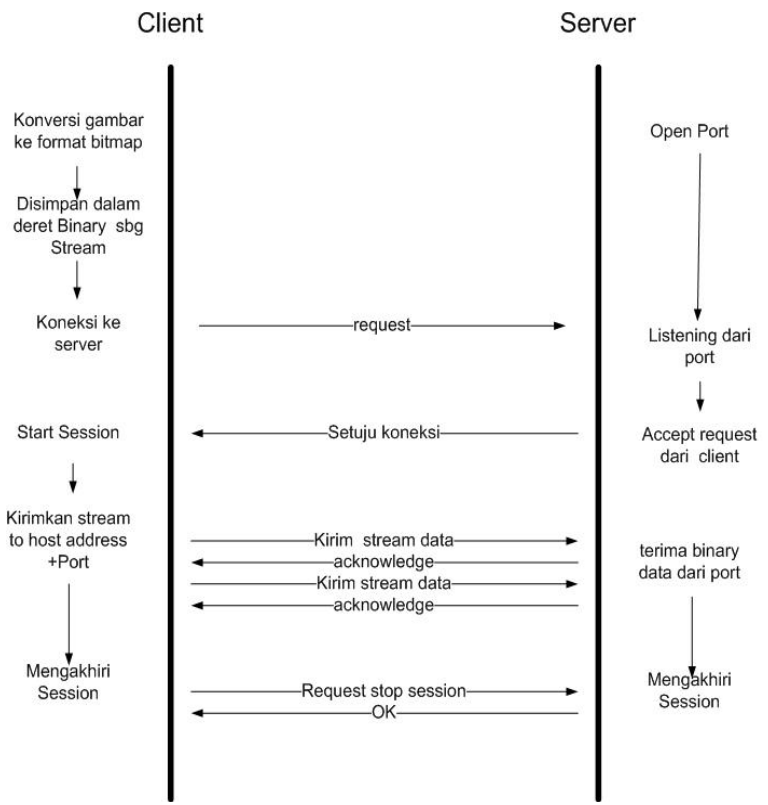

Gambar 5. Time Sequence Diagram Pengiriman Pesan Video

Sedangkan untuk file Audio yang diperoleh dari Microphone akan disimpan dalam bentuk file stream juga (berupa paket data). File stream ini akan dikirim ke komputer lain berdasarkan IP address yang dimasukkan. Ketika sampai pada komputer yang dimaksud maka komputer tersebut akan menerima paket data ini dan menyusun ulang paket-paket data yang dimaksud sehingga menjadi sebuah file suara yang dapat dikenali.

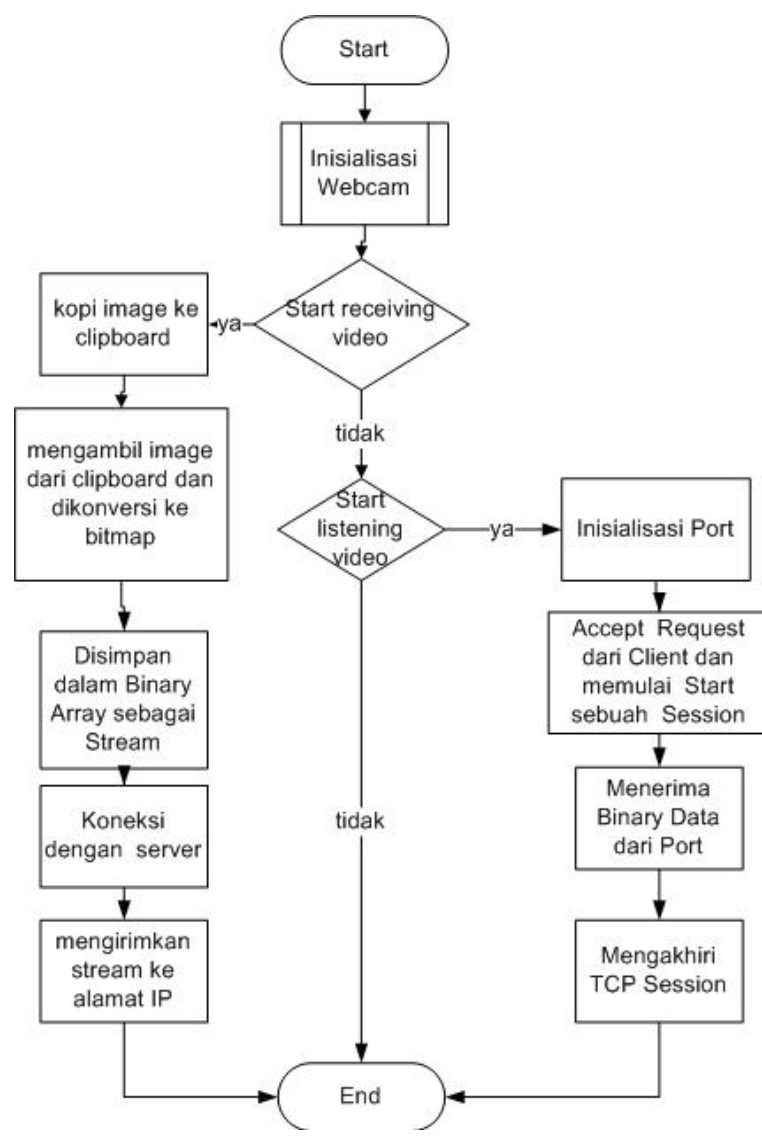

\section{Gambar 6. Flowchart pengiriman dan penerimaan message berupa video}

\section{IMPLEMENTASI DAN PENGUJIAN SISTEM}

Untuk aplikasi ini akan dikembangkan 2 jenis program yaitu Server dan Client dengan menggunakan Visual C\# 2005 Express Edition. Server akan dibagi menjadi beberapa class yang dibuat berdasarkan kegunaannya.

Class pada Server terdiri dari “class server” yang berfungsi untuk mengatur inisialisasi awal. "Class letter" yang berfungsi secara khusus untuk pengaturan pesan yang masuk ke dalam server, dan ditujukan kepada siapa pesan tersebut. Hal ini bertujuan agar pesan yang disampaikan tidak dikirimkan ke user yang lain. Class ini menggunakan tiga variabel bertipe string untuk pengiriman pesannya yang terdiri dari: from, to dan message. "Class accountfield" digunakan untuk mengatur secara spesifik mengenai account dari user, sehingga memungkinkan untuk menambahkan contact dan melihat status dari contact yang ada. Terdiri dari empat buah variabel dimana hanya dapat diakses dalam satu projek yang bersangkutan (internal). "Class connection” merupakan class yang mengatur koneksi antara server dengan setiap client yang ada.

Pengujian sistem yang dilakukan meliputi proses sign in pada aplikasi yang telah dibuat kemudian 
proses koneksi server dengan client dalam proses pengiriman pesan melalui multiple client juga pemanfaatan webcam pada program yang dibuat untuk mendukung video dan audio conference. Video yang akan ditampilkan pada client lainnya menggunakan frame picture yang dapat langsung dilihat pada komputer client lainnya sedangkan audio conference untuk dapat berkomunikasi layaknya menggunakan telepon.

Tampilan aplikasi server dapat dilihat pada Gambar 7.

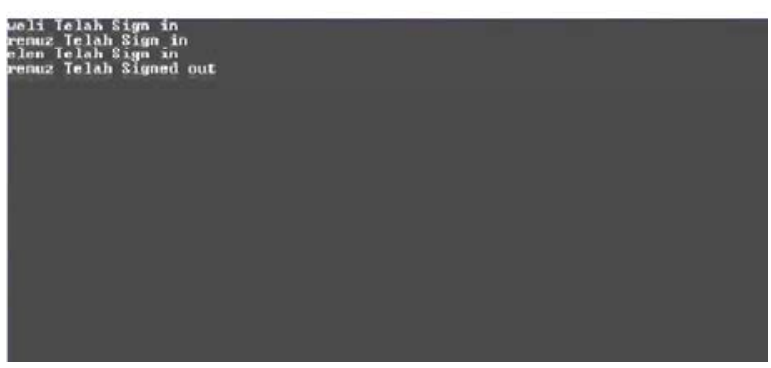

Gambar 7 Tampilan server

Tampilan aplikasi dapat dilihat pada di gambar 8, dimana tampak proses setting IP address komputer server pada komputer client.

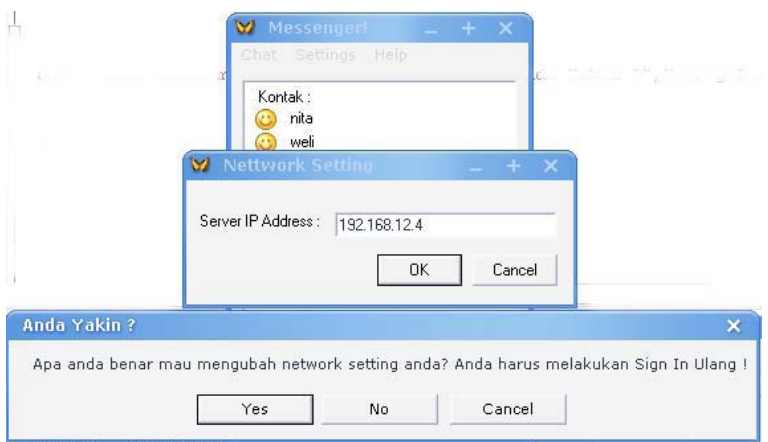

Gambar 8. Tampilan setting IP Address pada komputer client

Sebelum pengiriman pesan dilakukan, tiap user diharuskan untuk sign in, proses sign in hanya dapat dilakukan oleh user yang telah mendaftar atau registrasi. Proses registrasi akan menyimpan data user di server pada database class yaitu kedalam file bernama Dbacc.rx. Koneksi komputer client ke server berhasil dapat diuji dengan proses Sign in dan registrasi.

Setelah Sign in dilakukan, proses pengiriman message berupa text, video atau audio dapat dimulai.

Aplikasi pengiriman message berupa video dijalankan untuk melakukan percakapan dengan 2 tampilan video, yang pertama adalah tampilan dari webcam komputer sendiri dan dari webcam komputer lawan bicara.
Buat Account $\times$

\section{Registrasi}

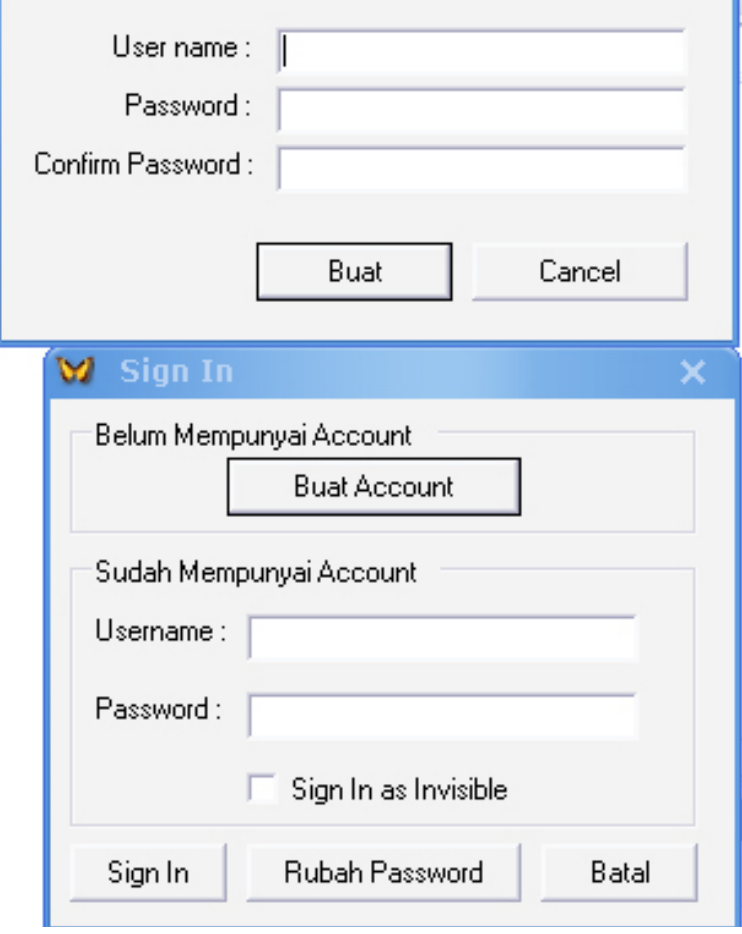

Gambar 9. User Interface Untuk Registrasi dan Sign in

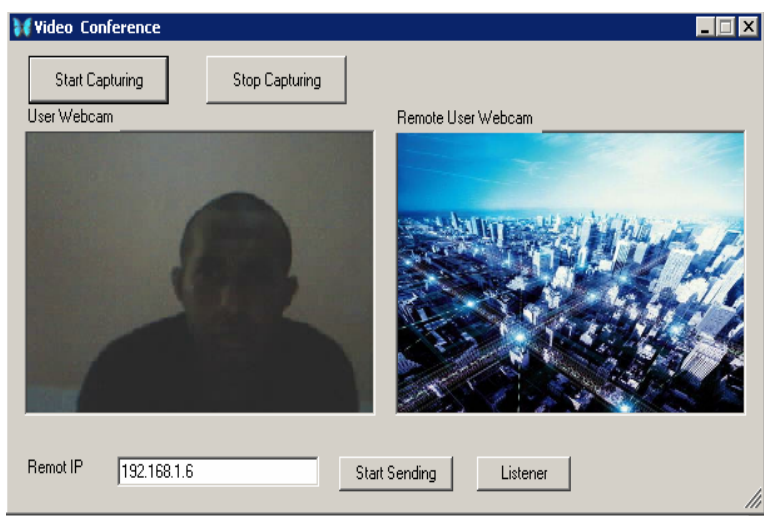

Gambar 10. Tampilan Pengiriman message Video

Dalam pengujian kali ini akan diuji pula mengenai waktu yang dibutuhkan untuk dapat menampilkan video dari remote client kepada local client. Jika waktu untuk melihat video remote user dapat lebih cepat maka program ini tidak perlu membuang waktu terlalu banyak.

Hal lain yang diuji adalah aplikasi pengiriman video dengan menggunakan webcam dengan spesifikasi yang berbeda yaitu Microsoft Livecam VX-500, Cretive Life! Cam Chat dan Logitech Quick Cam Communication Deluxe. Hasil dari ketiga merk dan tipe webcam tersebut menghasilkan kualitas video yang berbeda. 
Tabel 1. Tabel percobaan pengiriman message berupa video

\begin{tabular}{cc}
\hline No percobaan & Waktu yang diperlukan (detik) \\
\hline 1 & 02.17 \\
2 & 01.58 \\
3 & 03.10 \\
4 & 02.09 \\
5 & 03.69 \\
6 & 02.56 \\
7 & 02.68 \\
8 & 03.15 \\
9 & 02.76 \\
10 & 03.76 \\
\hline Rata-rata & 02.42 \\
\hline
\end{tabular}

Untuk pengiriman pesan berupa Audio, pada aplikasi ini hanya ditampilkan status-statusnya. Untuk pesannya sendiri digunakan microphone sebagai alat bantu. Ketika button call diaktifkan maka program akan langsung menjalankan prosedur yang menginisialisasi TAPI. Pada proses komunikasi ini komponen TAPI berperan penting dalam menentukan kontrol atas media, device dan juga proses transfer datanya. Call status berisi notification yang akan memberi tahu tentang segala proses komunikasi yang terjadi. Pada saat komunikasi dengan user lain. Suara yang dihasilkan sudah dapat didengar dengan sangat jelas dan mampu untuk dimengerti oleh client yang lainnya.

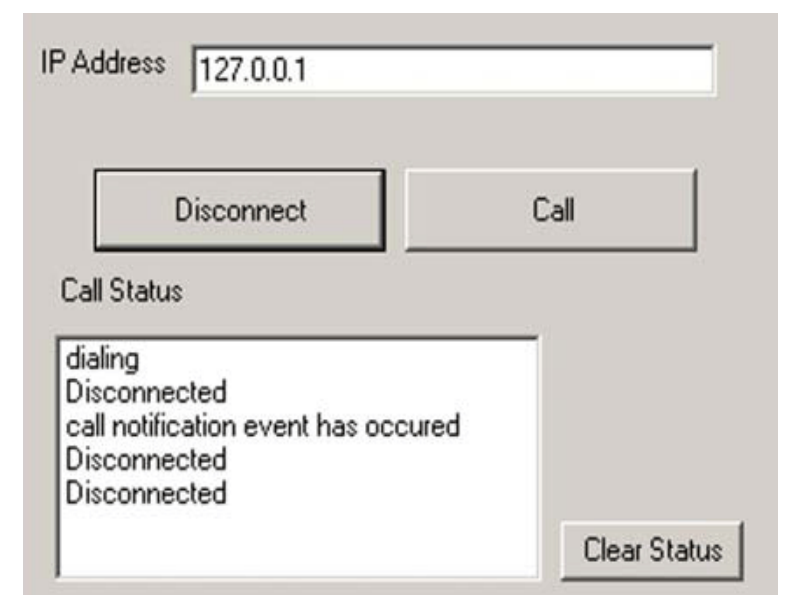

Gambar 11. Status pengiriman message berupa audio di komputer server

Pengujian lain yang dilakukan adalah pengujian pada network segment yang berbeda. IP address yang digunakan 202.43.254.4 dengan subnet mask
255.255.255.192 untuk client dan IP address 192.168.12.111 dengan subnet mask 255.255.255.0 untuk server. Hasil pengujian dengan skema di atas, semua aplikasi dapat berjalan dengan baik.

\section{KESIMPULAN}

Dari pembuatan aplikasi Corporate Messenger dapat diambil kesimpulan sebagai berikut:

1. Aplikasi dapat digunakan untuk kepentingan komunikasi internal perusahaan karena berjalan pada intranet tanpa tergantung pada ketersediaan jaringan Internet.

2. Pembuatan aplikasi yang didasarkan pada pengaturan IP address server mengakibatkan aplikasi dapat berjalan pada segment network yang berbeda.

3. Kualitas gambar yang akan ditampilkan pada video conference sangat tergantung dari kualitas webcam sendiri. Karena dalam program ini menggunakan komponen Windows (WebCam API) maka hasil yang ditampilkan adalah tidak akan direduksi oleh program.

\section{DAFTAR PUSTAKA}

1. Dev Articles 2009. Understanding .NET Remoting. Akses terakhir 18 Maret 2009 dari http://www.devarticles.com/c/a/ASP.NET/Unders tanding-.NET-Remoting/1/

2. Abdel-Qader, F.M. 2007. Examples to Create your Conferencing System In .NET, C\# VOIP \& Video Conferencing Systems Using H.323 and TAPI 3.

3. Microsoft Developer Network (MSDN). Telephony Application Programming Interface (TAPI) Overview. Akses terakhir 18 Januari 2009 dari http://msdn.microsoft.com/enus/library/ms734273(VS.85).aspx

4. Microsoft Developer Network (MSDN). Telephony Application Programming Interface (TAPI) V.3. Akses terakhir 18 Januari 2009 dari http://msdn.microsoft.com/enus/library/ms734215(VS.85).aspx

5. Shapiro, J. R. 1996. Computer Telephony Strategies. Wiley Publishing.

6. Stalling, W. 2006. Data and Computer Communication 8th 7 edition. Prentice Hall of India. 